\title{
PENGARUH IKLIM KOMUNIKASI ORGANISASI TERHADAP KOMITMEN ORGANISASI BERDASARKAN PERSPEKTIF APARATUR SIPIL NEGARA NON-STRUKTURAL
}

\section{THE EFFECT OF ORGANIZATIONAL COMMUNICATION CLIMATE ON ORGANIZATIONAL COMMITMENT BASED ON NON STRUCTURAL STATE CIVIL APPARATUS'S PERSPECTIVE}

\author{
Ane Dwi Septina \\ Pusat Penelitian dan Pengembangan Sosial, Ekonomi, Kebijakan, dan Perubahan Iklim \\ Badan Penelitian, Pengembangan, dan Inovasi Kementerian Lingkungan Hidup dan Kehutanan \\ Jalan Gunung Batu No. 5 Bogor, Indonesia \\ ane4n3@yahoo.com \\ Diterima tgl. 29/1/2019; Direvisi tgl. 30/11/2019; Disetujui tgl. 22/1/2020
}

\begin{abstract}
The organizational changes occur due to the emergency need of working production and effectiveness. A commitment from all of the organizational members is needed to cooperate and adapt towards the changes in order to maintain the performance's quality. This study was aimed to determine the influential impact of organizational communication climate on organizational commitment according to the non-structural civil servant's perspective, and also to determine the influential factors of organizational communication climate on organizational commitment. This is a quantitative study which was conducted at The Research Center for Biotechnology and Tree Improvement (BBPBPTH), Sleman in September-October 2015. The primary data was collected through survey. The random sampling was used to determine the sample which involved 96 participants. The data analysis used Partial Least Square-Structural Equation Modeling (PLS-SEM). The result confirmed that organizational communication climate had positive effect on organizational commitment. The trust and concern for high performance goals proved to affect significantly on organizational commitment, while listening in upward communication was not significantly affecting civil servant's organizational commitment.
\end{abstract}

Keywords: Organizational Communication Climate, Organizational Commitment, Government Organization.

\begin{abstract}
ABSTRAK
Perubahan dalam organisasi terjadi karena munculnya kebutuhan untuk peningkatan produktivitas dan efektivitas dalam bekerja. Komitmen yang tinggi dari seluruh anggota organisasi sangat diperlukan untuk bekerja sama dan beradaptasi terhadap perubahan tersebut untuk menjaga kualitas kinerja. Penelitian ini bertujuan untuk mengetahui pengaruh iklim komunikasi terhadap komitmen organisasi menurut perspektif aparatur sipil negara nonstruktural serta menentukan faktor-faktor iklim komunikasi organisasi yang berpengaruh terhadap komitmen organisasi. Penelitian ini merupakan penelitian kuantitatif yang dilaksanakan di Balai Besar Penelitian Bioteknologi dan Pemuliaan Tanaman Hutan (BBPBPTH) Sleman pada bulan September-Oktober 2015. Pengumpulan data primer dilaksanakan melalui survei. Teknik random sampling digunakan untuk menentukan jumlah sampel yang mencapai 96 partisipan. Teknik analisis data menggunakan Partial Least Square-Structural Equation Modeling (PLS-SEM). Hasil penelitian ini mengonfirmasi bahwa iklim komunikasi organisasi secara positif memengaruhi komitmen organisasi. Kepercayaan (trust) dan kekhawatiran terhadap capaian-capaian kinerja tinggi (concern for high performance goals) terbukti berpengaruh secara signifikan terhadap komitmen organisasi, sementara mendengarkan dalam komunikasi dari bawah ke atas (listening in upward communication) terbukti tidak berpengaruh secara signifikan terhadap komitmen organisasi aparatur sipil negara.
\end{abstract}

Kata Kunci: Iklim Komunikasi Organisasi, Komitmen Organisasi, Organisasi Pemerintah. 


\section{PENDAHULUAN}

Organisasi pemerintah wajib memberikan pelayanan berkualitas terhadap publik. Namun, seiring dengan kemajuan zaman, kadang-kadang perubahan dalam organisasi dapat memengaruhi ritme bekerja yang telah dipelihara sebelumnya dan dapat berimbas pada produktivitas organisasi. Perubahan tersebut dapat dimaknai sebagai perubahan yang mempengaruhi struktur organisasi, seperti bergabungnya dua organisasi pemerintah kedalam sebuah organisasi dengan nama baru; perubahan dalam penggunaan teknologi informasi; ataupun perubahan yang secara rutin terjadi seperti pergantian kepemimpinan. Permasalahan dari perubahan organisasi yang dapat menurunkan produktivitas organisasi adalah kekhawatiran akan gagalnya implementasi dari perubahan tersebut. Permasalahan lainnya adalah ketidakpercayaan dari para anggota organisasi terhadap perubahan yang akan dilakukan sehingga menimbulkan penolakan besar yang berimplikasi pada penurunan produktivitas organisasi. Oleh karena itu, diperlukan komitmen tinggi dari seluruh anggota organisasi di pemerintahan untuk beradaptasi dan bekerja sama melampaui perubahan guna menjaga kualitas kerjanya.

Komitmen organisasi menjadi salah satu kata kunci dalam kelangsungan sebuah organisasi. Anggota organisasi yang berkomitmen terhadap organisasinya akan berusaha dengan sungguhsungguh untuk menyukseskan organisasi. Oleh karena itu, pimpinan organisasi perlu memiliki strategi yang tepat untuk mendorong komitmen dari seluruh anggota organisasi. Menurut (Hosseini \& Talebian, 2015) komitmen organisasi merupakan salah satu aspek motivasi utama yang mengubah bentuk identitas anggota organisasi yang menyebabkan mereka mau berpartisipasi dan menyatu dalam organisasi sehingga menimbulkan rasa senang berada dalam organisasi tersebut.

Redding dalam Hardjana (2007) menyatakan bahwa situasi interaksional dan sikap positif yang mampu memotivasi pegawai dan meningkatkan kerja sama merupakan tanggung jawab dari manajemen. Motivasi positif yang kuat tersebut dapat dibangkitkan melalui keterbukaan, yang mampu memberikan kepercayaan, dukungan, tantangan, dan tanggung jawab pada diri pegawai sehingga mereka terbuka untuk membangun kerjasama antarsesama pegawai demi peningkatan kinerja yang lebih tinggi. Hal tersebut diperkuat oleh Rafiee, Bahrami, \& Entezarian (2015) dan Bahrami, Barati, Ghoroghchian, Montazer-alfaraj, \& Ezzatabadi (2016) bahwa staf yang berkomitmen dapat meningkatkan pertumbuhan dan keunggulan organisasi, sementara staf yang memiliki komitmen rendah dapat mengurangi kualitas pelayanan dan produk serta mengurangi performa organisasi.

Salah satu organisasi pemerintah yang mengalami perubahan struktur organisasi adalah Balai Besar Penelitian Bioteknologi dan Pemuliaan Tanaman Hutan (BBPBPTH). Pada akhir tahun 2014 Kementerian Kehutanan sebagai instansi penaungnya bergabung dengan Kementerian Lingkungan Hidup berdasarkan Peraturan Presiden No. 16 Tahun 2015. Penggabungan tersebut berimbas pada seluruh elemen organisasi. Kekhawatiran mengenai kemungkinan terjadinya perlambatan kinerja mulai muncul dari kelompok masyarakat sebagai salah satu stakeholder organisasi pemerintah. Menurut Walhi, penggabungan kementerian jelas membutuhkan penyesuaian restrukturisasi birokrasi, terlebih lagi sosok Menteri Siti Nurbaya yang merupakan orang baru sehingga akan terjadi pelambatan signifikan dalam isu lingkungan dan kehutanan (A. A. Palupi, 2014).

Kekhawatiran tersebut wajar diungkapkan mengingat kedua kementerian tersebut memiliki "pekerjaan rumah" yang masih menumpuk dan harus diselesaikan dengan segera. Pada kondisi ini pimpinan organisasi harus mampu mendorong seluruh anggota organisasi untuk menjaga komitmen organisasi mereka sehingga dapat beradaptasi dan bekerja sama guna meningkatkan kinerja organisasi. 
Melalui kajian manajemen komunikasi, komitmen organisasi dapat dibentuk melalui iklim komunikasi organisasi. Iklim komunikasi mencerminkan bagaimana pengalaman empiris pegawai tentang komunikasi dan perlakuan atasan terhadap dirinya, segenap pegawai, dan hubungannya dengan komunikasi, sikap dan pengertian yang berkembang di antara sesama pegawai (Hardjana, 2007). Berbagai penelitian tentang peranan iklim komunikasi dalam organisasi telah banyak dilakukan. Salah satu di antaranya adalah oleh Dillard, Wigand, \& Boster (1986) yang kemudian dipertajam oleh Donald P. Rogers (1987) dengan menambahkan variabel komitmen organisasi. Dari hasil penelitian tersebut diketahui bahwa "variabel Iklim komunikasi yang baik berpengaruh positif terhadap Komitmen organisasi”. Trombetta \& Donald P.Rogers (1988) kembali melihat hubungan antara Iklim komunikasi dan Komitmen organisasi dengan menambahkan variabel Kepuasan bekerja. Untuk mengukur iklim komunikasi organisasi, Trombetta dan Rogers menggunakan tiga dimensi iklim komunikasi yaitu Partisipasi dalam pengambilan keputusan (Participation in decision making), Keterbukaan dalam komunikasi (Communication openness), dan Kecukupan informasi (Information adequacy). Berdasarkan pengujian regresi berganda diketahui bahwa Kecukupan informasi (Information adequacy) muncul sebagai prediktor dari Komitmen organisasi (Trombetta \& Donald P.Rogers, 1988). Sementara penelitian yang dilakukan Guzley (1992) berjudul "Organizational Climate and Communication Climate: Predictors of Commitment to the Organization" yang mengambil sampel karyawan organisasi jasa yang berbasis di Southwest menemukan bahwa komitmen organisasi dipengaruhi oleh iklim organisasi dan iklim komunikasi. Diketahui pula Organizational clarity, Participation, dan Superior-subordiante communication dianggap memberi varians sebesar $41 \%$ pada komitmen organisasi, dan variabel yang muncul secara signifikan sebagai prediktor Komitmen organisasi adalah Participation dan Organizational clarity. Penelitian lain yang dilakukan oleh Fauzi \& Sarwoprasodjo (2014) terkait pengaruh iklim komunikasi organisasi yang dikaitkan dengan kinerja aparatur di pemerintahan desa menunjukkan bahwa Iklim komunikasi organisasi berpengaruh signifikan terhadap Kinerja aparatur, terutama pada variabel Kepercayaan, Pembuatan keputusan bersama, Keterbukaan dalam komunikasi ke bawah, Mendengarkan dalam komunikasi ke atas. Sementara Zulfah, Saridewi, \& Wira (2018) mengungkapkan Motivasi, Komunikasi dan Komitmen organisasi terbukti berpengaruh terhadap Kinerja karyawan di PT X dalam penelitian ini diketahui bahwa kinerja dapat meningkat jika komitmen organisasi terbentuk dengan baik yang timbul dari komunikasi yang juga dapat menumbuhkan motivasi.

Beberapa peneliti telah banyak melakukan penelitian terkait Trust dan Komitmen organisasi. Harrison \& Doerfel (2006) mengungkapkan bahwa Trust dan Komitmen merupakan proses tidak tetap yang lahir melalui hubungan simbolik dengan aktor organisasi karena interaksi tersebut memengaruhi komitmen organisasinya seiring dengan waktu. Dalam penelitian yang dilakukan Tan \& Lim (2009) ditemukan bahwa hubungan saling mempercayai antarpegawai merupakan prediktor tingkat kepercayaan pegawai terhadap organisasi yang dapat mengarah pada komitmen organisasi. Lebih lanjut hubungan saling mempercayai ini dibahas oleh Willemyns, Gallois, \& Callan (2003) dalam penelitiannya yang mencoba mengetahbui pola kepercayaan dan kekuasaan dalam hubungan manajer-anak buah. Dari hasil penelitian diketahui bahwa pokok komunikasi manajer, seperti dominasi, kekuatan untuk memaksa, kurangnya keinginan untuk mendengarkan, kurangnya dukungan untuk berempati dan ekspresi wajah yang mengancam dapat mempengaruhi persepsi "ingroupness" yang pada akhirnya mengikis tingkat kepercayaan. Penelitian yang dilakukan oleh Zeffane (2011) yang berjudul "Communication, Commitment \& Trust" berusaha memotret hubungan antara komunikasi, kepercayaan, dan komitmen karyawan pengolahan makanan di New South Wales dan diketahui bahwa komunikasi efektif antara manajemen dan karyawan penting dalam meningkatkan kepercayaan dan komitmen dalam organisasi. 
Hubungan Supportiveness (Dukungan) dan Komitmen Organisasi secara empirik diketahui berdasarkan penelitian yang dipublikasikan tahun 1986 oleh R. Eisenberger et.al dalam Tansky \& Cohen (2001) yang menyatakan bahwa dukungan organisasi yang dirasakan anggota organisasi memengaruhi komitmen organisasinya. Pada penelitian Tansky \& Cohen (2001) dukungan organisasi yang dimaksudkan diukur berdasarkan skala yang dikembangkan oleh Eisenberger, Huntington, Hutchinson dan Sowa di tahun 1986 yang meliputi persepsi karyawan tentang penilaian organisasi terhadap kontribusi mereka (pendapat atau masukan mereka untuk organisasi, hasil kerja) dalam organisasi dan kepedulian organisasi terhadap kesejahteraan mereka yang dilihat menurut sudut pandang para menejer. Hasil penelitian Tansky \& Cohen (2001) mengkonfirmasi kembali penelitian sebelumnya bahwa dukungan organisasi yang dirasakan anggota organisasi mempengaruhi komitmen organisasinya.

Meskipun sudah banyak hasil penelitian tentang iklim komunikasi organisasi dan hubungannya dengan komitmen organisasi, penelitian yang menganalisis keterbukaan dalam komunikasi ke bawah (Openness in Downward Communication) atau yang secara sederhana dapat dimaknai sebagai kemudahan akses informasi dalam penyelesaian tugas kerja yang diperoleh bawahan melalui komunikasi kepada atasan mereka sebagai salah satu dimensi iklim komunikasi organisasi terhadap komitmen organisasi belum banyak dilakukan. Umumnya peneliti hanya meneliti variabel iklim komunikasi organisasi secara kesatuan. Guney, Diker, Guney, Ayranci, \& Solmaz (2012) melakukan penelitian yang menganalisis tentang komunikasi organisasi melalui efek Open communication dan Close communication terhadap Komitmen organisasi yang diuji secara parsial. Hasilnya diketahui bahwa kedua jenis komunikasi tersebut mempengaruhi komitmen organisasi. Lebih lanjut, dalam penelitian terdahulu yang dilakukan Chen di tahun 2006 dalam (Guney et al., 2012) diketahui bahwa dalam organisasi dengan komunikasi organisasi yang terasa lebih terbuka, maka komitmen organisasi pegawainya pun cenderung tinggi. Penelitian yang dilakukan Guzley (1992) berjudul "Organizational Climate and Communication Climate : Predictors of Commitment to the Organization" yang mengambil sampel karyawan organisasi jasa yang berbasis di Southwest menemukan bahwa superior-subordiante communication dianggap memberi varians sebesar $41 \%$ pada komitmen organisasi. Hasil penelitian ini senada dengan yang dilakukan Guzley di tahun 1989 ketika menguji hubungan persepsi keterlibatan interaksi supervisor terhadap komitmen organisasi dimana persepsi keterlibatan interaksi supervisor diartikan sebagai partisipasi individu dengan individu lainnya melalui percakapan yang diukur menggunakan tiga dimensi yang dikembangkan Cegala et.al: Kemampuan memberikan perhatian (Attentiveness), Kemampuan untuk mengerti (Perceptiveness), kemampuan memberikan reaksi/kecekatan (Responsiveness). Diketahui bahwa Attentiveness dan Perceptiveness terbukti sebagai prediktor komitmen organisasi dari level pegawai sementara Responsiveness tidak terbukti sebagai prediktor dari komitmen organisasi dari level pegawai (Guzley,1992). Penelitian tentang komunikasi antara atasan dan bawahan yang dikaitkan dengan komitmen organisasi juga dilakukan oleh Van Noordwijk, Bizard, V. Wangpakapattanawong, P. Tata, Villamor, \& Leimona, (2014), dan juga oleh Wang (2011).

Diketahui bahwa Work-oriented Communication merupakan prediktor terhadap Affective commitment dan Normative commitment. Work-oriented Communication diukur berdasarkan tiga indikator yaitu kualitas yang dirasakan pegawai terhadap informasi stratejik pengembangan dan kebijakan organisasi, kualitas yang dirasakan pegawai terhadap Interaksi vertikal dengan manajemen (Downward dan Upward) serta kepuasan pegawai terhadap Management's responsiveness (Kecekatan manajemen) dalam menindaklanjuti masukan/saran.

Merujuk pada hasil penelitian terdahulu, diketahui bahwa anggota organisasi yang memiliki perhatian terhadap tujuan berkinerja tinggi mempengaruhi komitmen organisasi mereka, seperti 
penelitian yang dilakukan Meyer \& Allen (1997) menemukan bahwa individu yang berkomitmen dan menghargai visi misi organisasinya diketahui memiliki produktivitas yang meningkat. Penelitian tersebut sejalan dengan pendapat Mowday, Porter, \& Steers (1982) bahwa komitmen tinggi memiliki produktivitas dan rasa tanggungjawab yang tinggi untuk berkontribusi dalam pencapaian tujuan organisasi.

Sementara itu, Vuuren, Jong, \& Seydel (2007) melaporkan bahwa "komunikasi organisasi yang diwakilkan dari pihak manajer dapat mempengaruhi persepsi pegawai terhadap nilai dan kapabilitas organisasi" Kemudian, penelitian yang dilakukan Palupi (2004) mengungkapkan bahwa "kepuasan kerja dan iklim komunikasi organisasi secara bersama memberikan kontribusi yang bermakna terhadap komitmen organisasi". Iklim komunikasi organisasi berkembang berdasarkan persepsi dari seluruh anggota organisasi atas peristiwa komunikasi yang terjadi dalam organisasi tersebut. Persepsi tersebut kemudian dijadikan dasar anggota organisasi untuk bertindak dan bersikap dalam organisasi.

Berbeda dengan penelitian-penelitian terdahulu yang kebanyakan hanya mengambil iklim komunikasi organisasi sebagai satu kesatuan, pada penelitian yang menggunakan metode kuantitatif ini bertujuan untuk menjawab pengaruh iklim komunikasi organisasi terhadap komitmen organisasi dengan pengembangan dari penelitian sebelumnya melalui eksplorasi faktor-faktor dalam iklim komunikasi apa sajakah yang dapat mempengaruhi komunikasi organisasi. Aparatur sipil negara non struktural (ASN) dipilih sebagai responden pada penelitian ini karena sebagai pelaksana kebijakan perspektif mereka terhadap pemaknaan praktik komunikasi yang telah dilakukan para pimpinan berguna untuk memberikan masukan dan evaluasi para pimpinan guna peningkatan kinerja dan produktivitas organisasi.

Penelitian ini perlu dilakukan karena pada umumnya aparatur sipil negara (ASN) nonstruktural merupakan pemberi makna atas praktek komunikasi pimpinan dalam organisasi yang diwujudkan dalam aturan, kebijakan, dan pedoman yang mengikat seluruh anggota organisasi sementara penelitian dengan objek sejenis masih sangat minim didapatkan di Indonesia. Faktor-faktor tersebut perlu diteliti lebih lanjut sebagai bahan referensi pimpinan di organisasi pemerintah guna menentukan strategi komunikasi yang paling tepat diterapkan dalam organisasinya. Oleh karena itu, penelitian ini bertujuan untuk mengetahui pengaruh iklim komunikasi terhadap komitmen organisasi aparatur sipil negara nonstruktural di Balai Besar Penelitian Bioteknologi dan Pemuliaan Tanaman Hutan (BBPBPTH) dan mengetahui faktor-faktor dari iklim komunikasi organisasi yang berpengaruh terhadap komitmen organisasi.

\section{METODE PENELITIAN}

Iklim komunikasi dapat memberikan pengaruh penting terhadap produktivitas organisasi karena iklim mempengaruhi usaha dari seluruh anggota organisasi. Mengapa iklim komunikasi dikatakan mempengaruhi produktivitas? Jawabannya terdapat pada "usaha". Pace \& Faules (1993) berpendapat bahwa "Communication climate may be one of the most important influences on productivity in the organization, because climate affects the effort of an organization member".

Usaha atau effort yang dimaksud merujuk pada pendapat Roger S. Frantz dalam Pace \& Faules (1993) yang terdiri dari empat elemen, yakni (1) Activities (pekerjaan/tugas); (2) The pace (kecepatan pengerjaan tugas); (3) The quality (output atau hasil akhir); (4) The time (pola kerja). Analisis Frantz dalam Pace \& Faules (1993) terkait empat elemen tersebut adalah anggota organisasi memilih untuk menselang-selingkan jumlah usaha yang mereka berikan terhadap aktivitas di organisasi, yakni kecepatan pengerjaan tugas, perhatian terhadap pekerjaan mereka, kualitas hasil akhir, serta jumlah waktu yang mereka alokasikan untuk pekerjaan sebagai gambaran 
hasil reaksi anggota organisasi terhadap dorongan dari dalam jiwa dan atau dari lingkungan luar mereka bekerja. Bukti empiris tersebut menjelaskan bahwa jika iklim komunikasi yang berfungsi sebagai dorongan bagi anggota organisasi dan dirasakan baik, maka akan menimbulkan usaha dari anggota organisasi melalui komitmennya terhadap organisasi guna meningkatkan produktivitas.

Pada penelitian ini tipologi yang akan digunakan merujuk pada tipologi R. Wayne Pace dan Brent D. Peterson untuk variable iklim komunikasi organisasi serta tipologi komitmen organisasi milik Natalie Allen dan John Meyer.

Enam dimensi iklim komunikasi organisasi menurut R.Wayne Pace dan Brent D. Peterson dalam Pace \& Faules (1993), yaitu

1. Kepercayaan (Trust), pegawai semua tingkat harus berusaha keras untuk mengembangkan dan mempertahankan hubungan berdasarkan kepercayaan, keyakinan, dan kredibilitas;

2. Pembuatan keputusan bersama (Participative Decision Making), para pegawai semua tingkat di dalam organisasi harus memanfaatkan kesempatan dan berperan dalam mengomunikasikan semua masalah pada semua wilayah kebijakan organisasi yang relevan dengan kedudukan mereka;

3. Dukungan (Supportiveness), suasana keterusterangan yang mewarnai hubungan-hubungan dalam organisasi;

4. Keterbukaan dalam komunikasi ke bawah (Openness in Downward Communication), pegawai relatif mudah memperoleh informasi yang berhubungan langsung dengan tugas mereka saat itu;

5. Mendengarkan dalam komunikasi ke atas (Listening in Upward Communication), pegawai di semua tingkat atas dalam organisasi harus mendengarkan saran-saran atau laporan-laporan masalah yang dikemukakan pegawai di semua tingkat bawahan dalam organisasi secara berkesinambungan dengan pikiran terbuka;

6. Perhatian terhadap tujuan tujuan berkinerja tinggi (Concern for High Performance Goals), pegawai di semua tingkat dalam organisasi menunjukkan komitmen terhadap tujuan-tujuan berkinerja tinggi-produktivitas tinggi, kualitas tinggi, biaya rendah, dan juga menunjukkan perhatian besar pada anggota organisasi lainnya.

Sementara pada tipologi komitmen organisasi milik Natalie Allen dan John Meyer yang dipublikasikan pada tahun 1990 melihat bahwa berbagai konsep yang telah dikemukakan peneliti sebelumnya merefleksikan tiga tema umum, yakni kelekatan afektif, persepsi atas kerugian, dan rasa kewajiban. Berdasarkan ketiga tema tersebut, Allen dan Meyer membagi komitmen organisasi kedalam tiga dimensi. Penggolongan ini diperlukan karena setiap individu memiliki komitmen yang berbeda atas organisasinya. Perbedaan tersebut berdasarkan pada apa yang dirasakan masingmasing individu tersebut terhadap organisasinya.

Berdasarkan pemikiran tersebut lahirlah sebuah teori tentang komitmen organisasi yang diberi nama Three Component Model of Commitment. Tiga komponen komitmen organisasi tersebut adalah:

1. Affective Commitment (Komitmen Afektif), kunci dari komitmen ini adalah want to karena individu berkeinginan untuk terikat pada organisasi;

2. Continuance Commitment (Komitmen Berkelanjutan), kunci dari komitmen ini adalah need to, komitmen berdasarkan atas kebutuhan rasional;

3. Normative Commitment (Komitmen Normatif), kunci dari ought to, komitmen berdasarkan pada norma yang ada dalam diri pegawai sehingga menimbulkan keyakinan pada pegawai untuk bertanggung jawab terhadap organisasi.

Dalam menjelaskan komponen Komitmen Normatif, Allen, dan Meyer mengacu pada pendapat Weiner yang dipublikasikan pada tahun 1982. Weiner mendeskripsikan komitmen 
sebagai "akibat dari tekanan normatif yang sudah menyatu dalam diri individu untuk bertingkah laku dengan cara yang sesuai minat dan tujuan organisasi”" (Weiner dalam Meyer \& Allen, 1997).

Pada penelitian yang dilakukan oleh Sanusi (2012) di organisasi ANRI yang bertujuan untuk mengukur pengaruh iklim komunikasi organisasi dan motivasi terhadap komitmen organisasi melaporkan bahwaiklim komunikasi secara parsial terbukti berpengaruh terhadap komitmen organisasi. Dalam penelitian tersebut dibuktikan pula bahwa iklim komunikasi organisasi dan motivasi kerja secara simultan berpengaruh positif dan signifikan terhadap komitmen organisasi.

Dalam penelitian ini, peneliti menggunakan lima dari enam dimensi iklim komunikasi tanpa memasukan "pembuatan keputusan bersama" pada instrumen penelitian dengan pertimbangan bahwa hanya aparatur sipil negara dengan kompetensi tertentu yang dilibatkan dalam pembuatan keputusan bersama yang mempengaruhi kebijakan makro di lingkungan BBPBPTH yang kemudian kaitkan dengan komitmen organisasi dengan bentuk kerangka pikir sebagai berikut:

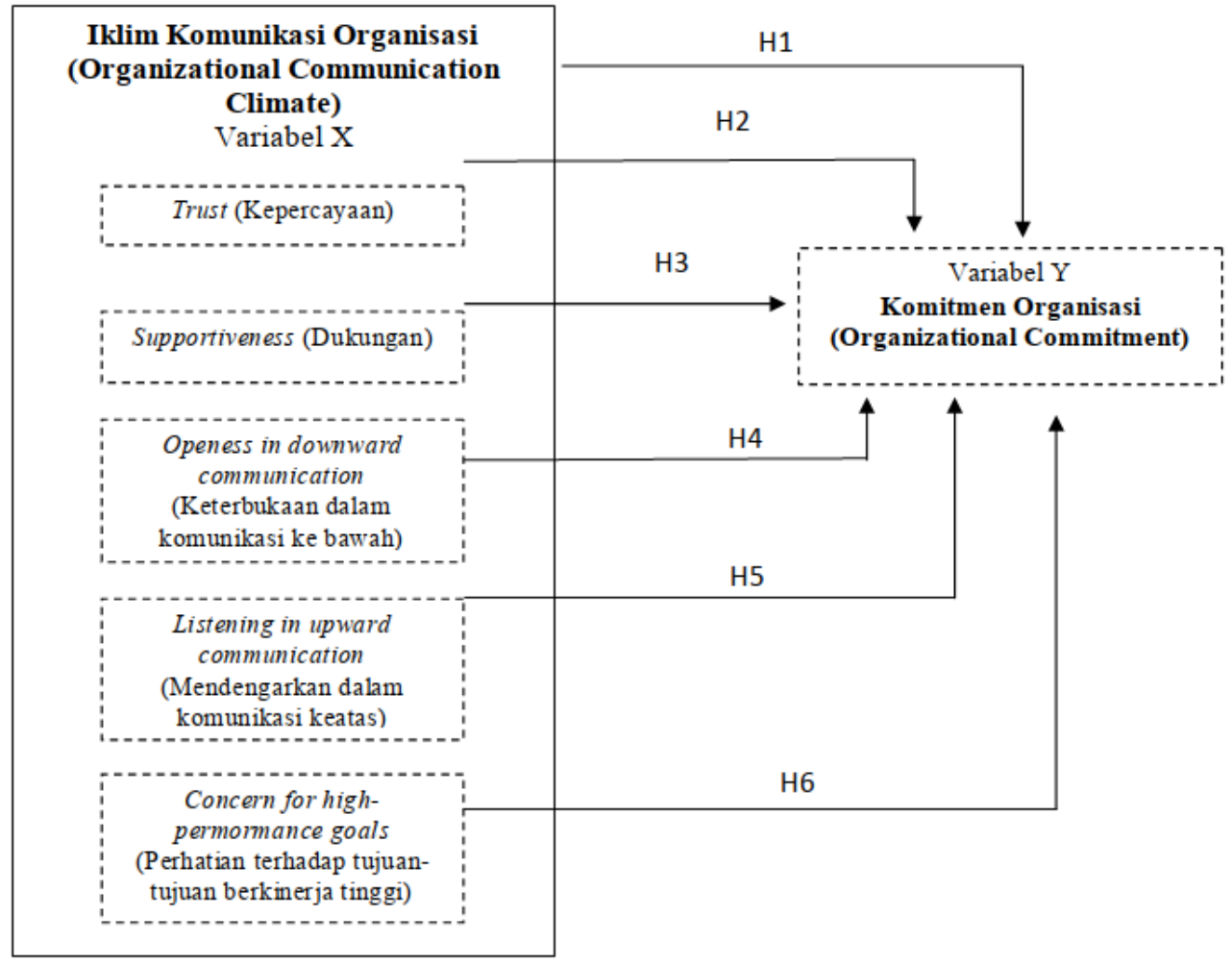

Sumber: dikembangkan dalam penelitian ini berdasarkan Sanusi (2012)

Gambar.1 Kerangka Pikir Penelitian

\subsection{Tempat dan Waktu Penelitian}

Penelitian ini mengambil lokasi di Sleman, Yogjakarta, pada Balai Besar Penelitian Bioteknologi dan Pemuliaan Tanaman Hutan (BBPBPTH). Populasi dalam studi ini meliputi aparatur sipil negara non-struktural di BBPBPTH, Sleman, Daerah Istimewa Yogyakarta. Penentuan sampel dilakukan secara acak terhadap populasi tersebut sejumlah 126 orang dan diperoleh hasil sebanyak 96 sampel berdasarkan perhitungan dengan menggunakan rumus Slovin. Penelitian ini dilakukan pada bulan September-Oktober 2015 dengan metode survei. Data yang dipergunakan dalam penelitian ini adalah data primer yang diperoleh melalui penyebaran kuesioner serta wawancara guna pelengkap data primer. 


\subsection{Validitas dan Reliabilitas}

Pengujian validitas dan reliabilitas pada penelitian ini menggunakan metode Partial Least Square (PLS) dengan memanfaatkan software SmartPLS, yaitu pengujian validitas dan reliabilitas indikator penyusun variabel melalui evaluasi model pengukuran atau measurement/outer model yang meliputi :

1) Uji Validitas Instrumen

Pada model penelitian ini, indikator yang digunakan bersifat refleksif sehingga diuji melalui validitas konvergen dan diskriminan dari indikator pembentuk konstruk latennya. Salah satu ciri indikator bersifat reflektif adalah jika peneliti menghilangkan satu indikator maka tidak akan mengubah makna konstruk (Latan dan Ghozali, 2012).

Pada pengujian validitas konvergen terdapat 3 tiga parameter yang perlu diperhatikan, sementara pada pengujian validitas diskriminan terdapat satu parameter agar analisis dapat dilanjutkan. Berikut adalah parameter-parameter dan rekomendasi nilai yang tersaji dalam tabel berikut ini.

Tabel 1. Parameter Uji Validitas

\begin{tabular}{|c|c|c|c|c|}
\hline No & $\begin{array}{l}\text { Validitas } \\
\text { Variabel } \\
\end{array}$ & Parameter & Rekomendasi Nilai & Sumber \\
\hline \multirow[t]{4}{*}{1} & Konvergen & Loading Factor & Lebih dari 0,60 & $\begin{array}{l}\text { Chin dan Hair et } \\
\text { al dalam Latan } \\
\text { dan Ghozali } \\
\text { (2012) }\end{array}$ \\
\hline & & Variance & Lebih dari 0,50 . & Hair et al dalam \\
\hline & & Extracted $(A V E)$ & & $\begin{array}{c}\text { Latan dan } \\
\text { Ghozali (2012) }\end{array}$ \\
\hline & & Communality & Lebih dari 0,50 . & $\begin{array}{c}\text { Chin dalam Latan } \\
\text { dan Ghozali } \\
\text { (2012) }\end{array}$ \\
\hline 2 & Diskriminan & Cross Loading & $\begin{array}{l}\text { Loading Factor } \\
\text { konstruk yang dituju } \\
>\text { >oading factor kepada } \\
\text { konstruk lain. }\end{array}$ & $\begin{array}{c}\text { Chin dan Hair et } \\
\text { al dalam Latan } \\
\text { dan Ghozali } \\
\text { (2012) }\end{array}$ \\
\hline
\end{tabular}

Loading factor adalah korelasi antara skor item/skor komponen dengan skor konstruk (Jogiyanto, 2011). Nilai loading factor atau outer loadings berasal dari indikator-indikator yang mengukur konstruk tersebut. Communality adalah ukuran kualitas model pengukuran pada tiap blok variabel laten yang dihasilkan dalam proses iterasi algorithm Partial Least Square (PLS). Selain itu, $A V E$ adalah rerata persentase skor varian yang diekstrasi dari seperangkat variabel laten yang diestimasi melaui loading standardize indikatornya dalam proses iterasi algorithm Partial Least Square (PLS) (Hair et al, 2011). Nilai Average Variance Extracted (AVE) direkomendasikan harus lebih besar dari 0,5 dimana artinya $50 \%$ atau lebih variance dari indikator dapat dijelaskan (Latan dan Ghozali, 2012). Sementara pada validitas diskriminan, berprinsip bahwa pengukurpengukur konstruk yang berbeda seharusnya tidak berkolerasi dengan tinggi. Terdapat beberapa cara untuk menguji validitas diskriminan namun pada penelitian ini, peneliti akan mengujinya melalui niai cross loading. Menurut Latan dan Ghozali (2012), cara untuk menguji validitas diskriminan dengan indikator refleksif yaitu dengan melihat nilai cross loading untuk setiap variabel harus lebih besar dari 0,6. 


\section{2) Uji Reliabilitas Instrumen}

Selain uji validitas, pada analisis metode Partial Least Square (PLS) juga dilakukan pengujian reliabilitas konstruk. Uji reliabilitas dilakukan untuk membuktikan ketepatan dan konsistensi alat ukur dalam mengukur konstruk karena pada indikator reflektif dapat dilakukan dengan dua cara, yaitu dengan cronbach's alpha dan composite reliability. Namun, penggunaan Cronbach's alpha untuk menguji reliabilitas konstruk akan memberikan nilai yang lebih rendah (under estimate) sehingga lebih disarankan untuk menggunakan composite reliability dalam menguji reliabilitas suatu konstruk (Latan dan Ghozali, 2012). Hal ini selaras dengan pendapat Jogiyanto (2011) yang mengatakan bahwa Cronbach's alpha digunakan untuk mengukur batas bawah nilai reliabilitas suatu konstruk, sedangkan composite reliability mengukur nilai sesungguhnya reliabilitas suatu konstruk sehingga composite reliability dianggap lebih baik dalam melakukan penilaian reliabilitas suatu konstruk. Berdasarkan pendapat tersebut, pada penelitian ini peneliti akan menggunakan nilai composite reliability dalam pengujian reliabilitas. Terdapat rekomendasi nilai yang dapat digunakan sebagai acuan dalam pengujian reliabilitas, rekomendasi nilai tersebut dapat dilihat pada Tabel 2 berikut ini.

Tabel 2. Parameter Uji Reliabilitas

\begin{tabular}{cccl}
\hline No & Parameter & \multicolumn{1}{c}{ Rekomendasi Nilai } & \multicolumn{1}{c}{ Sumber } \\
\hline $\mathbf{1}$ & Cronbach's Alpha & Lebih dari 0,70 & Chin dan Hair et al dalam \\
& & & Latan dan Ghozali (2012) \\
$\mathbf{2}$ & Composite Reliability & Lebih dari 0,70 & Chin dan Hair et al dalam \\
& & & Latan dan Ghozali (2012) \\
\hline
\end{tabular}

\subsection{Teknik Analisis Data}

Teknik analisis yang digunakan untuk menjawab hipotesis adalah Partial Least SquareStructural Equation Modeling (PLS-SEM). PLS-SEM bertujuan untuk menguji hubungan prediktif antarkonstruk dengan melihat apakah ada hubungan atau pengaruh antarkonstruk tersebut (Latan \& Ghozali, 2012). Peneliti memilih menggunakan PLS-SEM karena sesuai untuk menganalisis model pada penelitian ini yang merupakan pengembangan dari model penelitian sebelumnya. Latan \& Ghozali (2012) mengatakan bahwa pada penggunaan PLS-SEM pengujian dapat dilakukan tanpa dasar teori yang kuat dan mengabaikan beberapa asumsi (nonparametrik) dan parameter ketepatan model prediksi dilihat dari nilai koefisien determinasi sehingga PLS-SEM sangat tepat digunakan pada penelitian yang bertujuan untuk mengembangkan teori.

Pengujian validitas dan reabilitas menggunakan Second Order Confirmatory Factor Analysis yang diketahui bahwa dimensi Dukungan (Supportiveness) dan Keterbukaan dalam komunikasi ke bawah (Openness in Downward Communication) menghasilkan nilai faktor loading dibawah 0,6, maka didrop dari model sehingga dapat disimpulkan bahwa indikator variabel yang telah teruji validitas dan reliabilitasnya dan akan dianalisis lebih lanjut sebagai hipotesis pada penelitian ini adalah variabel Iklim komunikasi organisasi yang diukur melalui dimensi Kepercayaan (Trust), Mendengarkan dalam komunikasi keatas (Listening in upward communication), Perhatian terhadap tujuan-tujuan berkinerja tinggi (Concern to high performance goals) dan variabel Komitmen organisasi.

Berdasarkan pada temuan penelitian di atas yang mengonfirmasikan pengaruh antara iklim komunikasi organisasi terhadap komitmen organisasi serta pengaruh faktor-faktor pembentuk iklim komunikasi organisasi terhadap komitmen organisasi, data yang akan dianalisis dapat dirumuskan menjadi hipotesis sebagai berikut : 
H1 : Iklim komunikasi organisasi berpengaruh terhadap komitmen organisasi aparatur sipil negara nonstruktural di BBPBTH.

$\mathrm{H} 2$ : Trust berpengaruh terhadap komitmen organisasi aparatur sipil negara nonstruktural di BBPBTH.

H3 : Supportiveness berpengaruh terhadap komitmen organisasi aparatur sipil negara nonstruktural di BBPBTH.

H4 : Openness in Downward Communication berpengaruh terhadap komitmen organisasi aparatur sipil negara nonstruktural di BBPBTH.

H5 : Listening in Upward Communication berpengaruh terhadap komitmen organisasi aparatur sipil negara nonstruktural di BBPBTH.

H6 : Concern for High Performance Goals berpengaruh terhadap komitmen organisasi aparatur sipil negara nonstruktural di BBPBTH.

Pada pengujian hipotesis 1satu variabel yang digunakan adalah variabel iklim komunikasi organisasi yang dijabarkan dengan lima, yaitu dimensi Kepercayaan (Trust), Dukungan (Supportiveness), Keterbukaan dalam komunikasi ke bawah (Openness in Downward Communication), Mendengarkan dalam komunikasi ke atas (Listening in Upward Communication), Perhatian terhadap tujuan-tujuan berkinerja tinggi (Concern for High Performance Goals) sebagai variabel bebas dan variabel komitmen organisasi yang dijabarkan dengan tiga dimensi (Komitmen Afektif (Affective Commitment), Komitmen Berkelanjutan (Continuance Commitment), dan Komitmen Normatif (Normative Commitment) sebagai variabel terikat.

Pada pengujian hipotesis 2-6 penelitian menggunakan 6 variabel yang merupakan dimensi dari iklim komunikasi organisasi meliputi variabel Kepercayaan (Trust), Dukungan (Supportiveness), Keterbukaan dalam komunikasi ke bawah (Openness in Downward Communication), Mendengarkan dalam komunikasi keatas (Listening in Upward Communication), Perhatian terhadap tujuan-tujuan berkinerja tinggi (Concern for High Performance Goals), dan variabel komitmen organisasi. Masing-masing variabel akan diukur berdasarkan indikator-indikator yang dijabarkan dalam instrumen kuesioner. Pengukuran variabel komitmen organisasi pada penelitian ini menggunakan Organizational commitment questionaire Allen dan Meyer versi original yang telah disesuaikan dengan penelitian ini, sementara pengukuran iklim komunikasi organisasi pada penelitian ini menggunakan Communication Climate Inventory milik $\mathrm{R}$ Wayne Pace dan Brent D. Peterson yang telah dimodifikasi ke dalam bahasa Indonesia.

\section{HASIL DAN PEMBAHASAN}

Kuesioner yang disebarkan dalam penelitian ini adalah sebanyak 96 eksemplar sesuai dengan jumlah sampel yang telah ditetapkan sebelumnya. Prosentase tingkat pengembalian kuesioner adalah $100 \%$ dan keseluruhan kuesioner menunjukan kelayakan untuk pengolahan data selanjutnya.

\section{Analisa Pengujian Hipotesis 1 (Satu)}

Berikut adalah hasil pengujian hipotesis 1 dengan bantuan software SmartPLS versi 2.0 M3, yakni

Tabel 3. Nilai $R$-Square Konstruk H1 (satu)

\begin{tabular}{|c|c|c|}
\hline Konstruk & R Square & Model Prediksi \\
\hline KO & 0,264565 & lemah \\
\hline \multicolumn{3}{|c|}{ KO $=$ Komitmen organisasi } \\
\hline
\end{tabular}




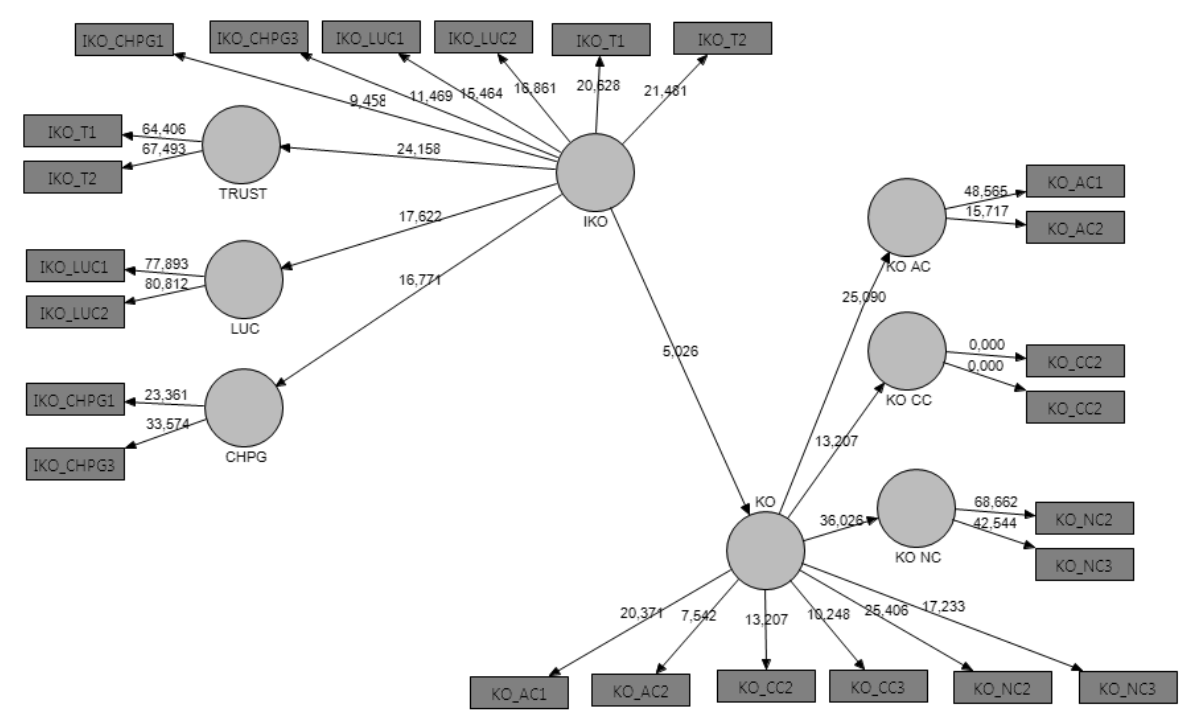

Gambar 2. Path Diagram atas T-Statistic H1 (satu)

Tabel 4. Hasil Analisis Bootstrap H1 (satu)

\begin{tabular}{|c|c|c|c|c|c|}
\hline \multirow{2}{*}{ Hipotesis } & \multicolumn{2}{|c|}{ Path/Jalur } & \multirow{2}{*}{$\begin{array}{c}\text { Original Sample } \\
(\text { (O) }\end{array}$} & \multirow{2}{*}{$\begin{array}{c}T-\text { Value } \\
(\mathrm{t})\end{array}$} & \multirow{2}{*}{$\begin{array}{l}\text { Hasil Pengujian } \\
\qquad \begin{array}{c}\alpha=0,05 \\
\text { Hair et. al. (2011) }\end{array}\end{array}$} \\
\hline & Dari & $\mathrm{Ke}$ & & & \\
\hline $\mathrm{H} 1$ & IKO & $\mathrm{KO}$ & 0,514359 & 5,025700 & Signifikan \\
\hline
\end{tabular}

Pada pengujian model struktural hipotesis 1 diketahui bahwa Iklim Komunikasi Organisasi (IKO) terbukti berpengaruh secara signifikan terhadap Komitmen Organisasi (KO) di BBPBPTH. Temuan ini didasarkan atas nilai $t$-value yang lebih besar daripada nilai $t$-tabel yakni 5,025700, maka dapat dinyatakan bahwa H0 ditolak. Nilai $R$-Square $=0,264565$ menerangkan bahwa model hipotesis 1 ini dapat dikatakan dalam skala lemah berdasarkan dari penjelasan Chin dalam Latan dan Ghozali, (2012) dimana bahwa model yang kuat ditunjukkan dengan nilai 0,67; model yang moderate ditunjukkan dengan nilai 0,33 dan model yang lemah ditunjukkan dengan nilai 0,19. Sementara arah hubungan iklim komunikasi organisasi terhadap komitmen organisasi dinyatakan positif berdasarkan nilai Original Sample $(\mathrm{O})=0,514359$ dengan tingkat signifikansi $\alpha=0,05$ sehingga dapat disimpulkan bahwa semakin baik iklim komunikasi organisasi, maka komitmen organisasi di BBPBPTH akan semakin baik pula, begitu juga sebaliknya, semakin buruk iklim komunikasi organisasi maka komitmen organisasi di BBPBPTH akan memburuk pula. Hasil penelitian ini menguatkan penelitian yang dilakukan Trombetta \& Rogers (1988), Guzley (1992), Palupi (2004), dan Sanusi (2012).

Dikatakan bahwa iklim komunikasi dapat menjadi pedoman bagi pimpinan untuk memahami perilaku anggota organisasi. Iklim komunikasi organisasi timbul berdasarkan interaksi dalam organisasi yang dipersepsikan oleh anggota organisasi. Ketika iklim komunikasi terkondisikan dengan baik, anggota organisasi secara tidak langsung terstimuli sehingga akan terbentuk sikap mental positif untuk berusaha lebih baik lagi. Pada penelitian ini, diketahui bahwa nilai $R$-Square yang menjelaskan tentang seberapa besar iklim komunikasi organisasi dapat menjelaskan komitmen organisasi pada model ini hanya sebesar $26,46 \%$. Hal ini dapat dijelaskan dengan merujuk data demografi responden karena mayoritas responden BBPBPTH berada pada rentang usia 40-49 tahun $(35,42 \%)$ dan masih dapat digolongkan pada rentang usia produktif. Jika dilihat 
menggunakan kriteria empat tahapan usia pengembangan karier milik Douglas.T Hall, responden berada di antara dua tahap tahapan usia pengembangan karier, yaitu masa kemampanan (establishment) yang berada pada rentang usia 25 tahun - 44 tahun dimana individu mulai memahami lingkungan kerja dan tuntutan organisasional serta berjuang untuk membangun eksistensinya dalam suatu organisasi, serta pada masa pemeliharaan (maintenance) yang berada pada rentang usia 45- 64 tahun karena pada masa ini individu tidak lagi berusaha untuk menetapkan tempat bagi dirinya di organisasi, tetapi berusaha mempertahankan posisinya. Pada tahapan ini, umumnya individu sudah memiliki pandangan tertentu terhadap organisasi yang tidak mudah digoyahkan. Dengan demikian, dapat diintrepretasikan bahwa pada organisasi BBPBPTH, dorongan yang bersumber pada iklim komunikasi organisasi tidak cukup besar bagi aparatur sipil negara non struktural BBPBPTH untuk meningkatkan komitmen organisasi mereka.

\section{Analisis Pengujian Hipotesis 2, Hipotesis 5, dan Hipotesis 6}

Tabel 5. Nilai $R$-Square Konstruk H2, H5, dan H6

\begin{tabular}{|c|c|c|}
\hline Konstruk & R Square & Model Prediksi \\
\hline KO & 0,502281 & moderate \\
\hline
\end{tabular}

Sumber : Data Primer diolah

$\mathrm{KO}=$ Komitmen organisasi

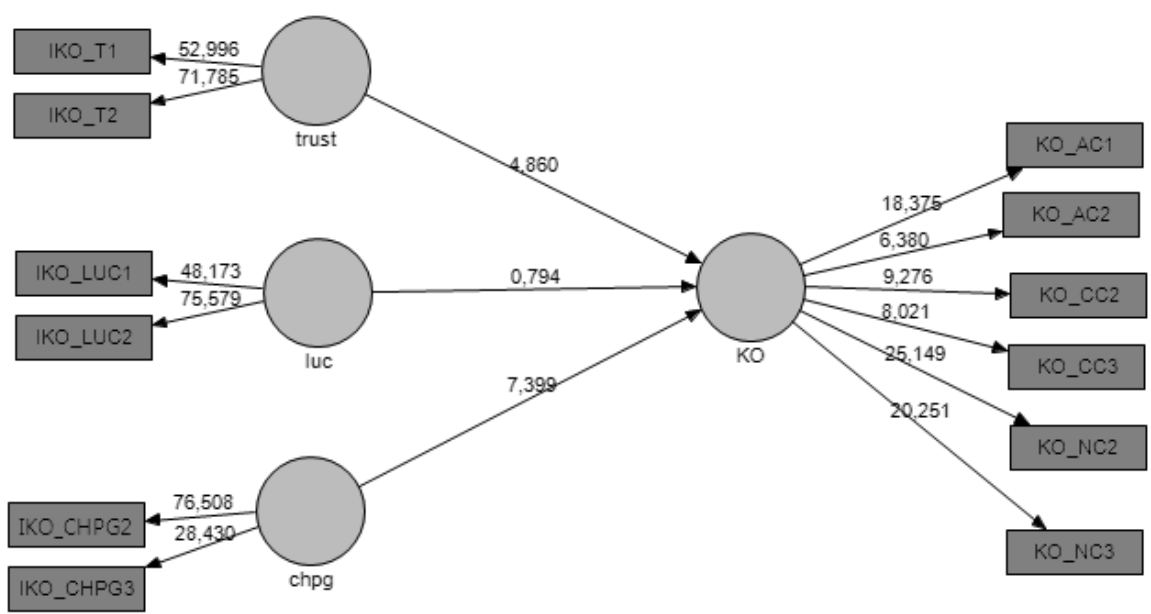

Gambar 3. Data Primer diolah Path Diagram atas T-Statistic H2, H5, dan H6

Tabel 6 . Hasil Analisis Bootstrap H2, H5, dan H6

\begin{tabular}{cccccc}
\hline Hipotesis & \multicolumn{2}{c}{ Path/Jalur } & Original Sample (O) & $\begin{array}{c}\text { T }- \text { Value } \\
(\mathbf{t})\end{array}$ & $\begin{array}{c}\text { Hasil Pengujian } \\
\boldsymbol{\alpha}=\mathbf{0 , 0 5} \\
\end{array}$ \\
\cline { 2 - 3 } & Dari & Ke & & & Hair et. al. (2011) \\
\hline H2 & TRUST & KO & 0,367048 & 4,859737 & Signifikan \\
H5 & LUC & KO & $-0,062601$ & 0,793637 & Tidak Signifikan \\
H6 & CHPG & KO & 0,551887 & 7,399264 & Signifikan \\
\hline
\end{tabular}

Berdasarkan penelitian yang dilakukan Pace dan Peterson (Pace \& Faules, 1993), Kepercayaan (Trust), Mendengarkan dalam komunikasi keatas (Listening in upward communication), dan Perhatian terhadap tujuan-tujuan berkinerja tinggi (Concern to high performance goals) merupakan 
dimensi-dimensi yang menyusun Iklim Komunikasi Organisasi, tetapi belum banyak penelitian yang meneliti tentang dimensi iklim komunikasi organisasi yang dikaitan dengan komitmen organisasi. Pada penelitian ini pengujian hipotesis 2 dan hipotesis 6 dapat dibuktikan bahwa Kepercayaan (Trust) terbukti berpengaruh secara signifikan terhadap Komitmen Organisasi (KO) aparatur sipil negara di BBPBPTH berdasarkan nilai $t$-value yang lebih besar daripada nilai $t$-tabel yakni 4,859737 dengan arah hubungan dinyatakan positif berdasarkan nilai Original Sample $(O)=$ 0,367048 dengan tingkat signifikansi $\alpha=0,05$ dan perhatian terhadap tujuan-tujuan berkinerja tinggi (concern to high performance goals ) terbukti berpengaruh secara signifikan terhadap komitmen organisasi aparatur sipil negara di BBPBPTH nilai $t$-value yang lebih besar daripada nilai t-tabel yakni 7,399264 dengan arah hubungan dinyatakan positif berdasarkan nilai Original Sample $(\mathrm{O})=0,551887$ dengan tingkat signifikansi $\alpha=0,05$. Kemampuan variabel kepercayaan (trust), mendengarkan dalam komunikasi keatas (listening in upward communication), dan variabel perhatian terhadap tujuan-tujuan berkinerja tinggi (concern to high performance goals) dalam menjelaskan komitmen organisasi dibuktikan dengan nilai $R$-Square $=0,502281$. Merujuk kepada penjelasan Chin dalam Latan \& Ghozali (2012), dapat dikatakan model penelitian ini berada pada skala moderate ditunjukkan dengan nilai lebih dari 0,33.

Kepercayaan merupakan landasan dari kerjasama dalam berorganisasi. Apabila kepercayaan sudah terbentuk antar anggota organisasi, pertukaran informasi akan menjadi semakin mudah sehingga memudahkan koordinasi. Hasil penilaian persepsi responden terhadap iklim komunikasi organisasi BBPBPTH yang menggunakan Communication Climate Inventory milik Pace dan Peterson yang telah disesuaikan menyatakan bahwa mayoritas responden merasa bahwa dalam organisasinya telah terbentuk rasa saling percaya antara pegawai nonstruktural dan pegawai struktural selaku pimpinan mereka dan hanya sekitar 10,94\% responden yang tidak merasakannya. Dalam organisasi BBPBPTH, tampaknya baik aparatur sipil negara struktural (pimpinan) maupun aparatur sipil negara nonstruktural telah dapat menjalin komunikasi yang baik yang mewujudkan kepercayaan. Hasil penelitian diatas melengkapi penelitian yang dilakukan Zeffane (2011) karena diketahui bahwa komunikasi efektif antara manajemen dan karyawan penting dalam meningkatkan kepercayaan dan komitmen dalam organisasi dan melengkapi penelitian yang dilakukan Tan \& Lim (2009) yang menyimpulkan bahwa hubungan saling mempercayai diantara pegawai merupakan prediktor tingkat kepercayaan pegawai terhadap organisasi yang dapat mengarah pada komitmen organisasi. Redding dalam Hardjana (2007) menyatakan bahwa manajemen memiliki tanggung jawab untuk menciptakan 'situasi interaksional dan sikap positif' yang dapat memotivasi karyawan serta meningkatkan kerjasama. Motivasi positif yang kuat dapat dibangkitkan dengan keterbukaan yang mampu memberikan kepercayaan, dukungan, tantangan, dan tanggung jawab pada diri karyawan sehingga mereka terbuka untuk membangun kerjasama antar sesama karyawan demi peningkatan kinerja yang lebih tinggi.

Pada pengujian pengaruh mendengarkan dalam Komunikasi ke atas (Listening in upward communication) terhadap Komitmen organisasi diperoleh hasil bahwa mendengarkan dalam Komunikasi keatas (Listening in upward communication) terbukti tidak berpengaruh secara signifikan terhadap komitmen organisasi aparatur sipil negara di BBPBPTH. Temuan ini didasarkan atas nilai $t$-value yang dihasilkan lebih kecil daripada nilai t-tabel yakni 0,793637. Variabel Mendengarkan dalam komunikasi keatas (Listening in upward communication) diukur melalui persepsi pegawai terhadap kemampuan pimpinan (pejabat struktural) dalam menindaklanjuti informasi dan saran pegawai (Responsiveness) serta kemampuan pimpinan (pejabat struktural) dalam mendengarkan informasi dan saran pegawai (Attentiveness). Pada penelitian yang dilakukan Ruth Guzley di tahun 1989 menemukan Kemampuan atasan memberikan perhatian (Attentiveness) terbukti sebagai prediktor komitmen organisasi dari level pegawai/staf 
namun kemampuan atasan memberikan reaksi/kecekatan (Responsiveness) tidak terbukti sebagai prediktor dari komitmen organisasi dari level pegawai/staf (Guzley, 1992). Untuk menjelaskan mengapa Mendengarkan dalam komunikasi keatas (Listening in upward communication) bukan prediktor dari Komitmen organisasi aparatur sipil negara nonstruktural di BBPBPTH, peneliti melakukan wawancara informal terhadap beberapa responden dengan pendidikan SLTA karena berdasarkan hasil demografi responden, mayoritas responden pada penelitian ini memiliki pendidikan terakhir SLTA. Dari hasil analisis penilaian responden yang disandingkan dengan hasil wawancara diketahui bahwa meskipun mayoritas responden berpendapat bahwa pimpinan di BBPBPTH memberikan perhatian dan merespon terhadap informasi dan saran yang mereka sampaikan dengan baik, tetapi pada umumnya responden mengaku jarang berkonsultasi dengan atasan terkait pekerjaan yang mereka tangani dikarenakan mereka merasa mampu menangani pekerjaan tersebut tanpa perlu melibatkan atasan. Berdasarkan hasil wawancara diketahui tanggung jawab pekerjaan responden berada pada level pelaksana, seperti supir, satpam, teknisi litkayasa, dan pramu kantor.

Pengujian terakhir yang dilakukan pada penelitian ini adalah pengujian pengaruh variabel perhatian terhadap Tujuan-tujuan berkinerja tinggi (Concern for high performance goals) terhadap Komitmen Organisasi aparatur sipil negara nonstruktural di BBPBPTH. Hasil penelitian ini memberikan kontribusi empiris terhadap pernyataan Mowday et al.(1982) bahwa "komitmen tinggi memiliki produktivitas dan rasa tanggung jawab yang tinggi untuk berkontribusi dalam pencapaian tujuan organisasi" serta memperkuat pendapat Meyer \& Allen (1997) bahwa "individu yang berkomitmen dan menghargai visi misi organisasinya diketahui memiliki produktivitas yang meningkat".

Hampir seluruh responden menyatakan persetujuannya terhadap perhatian terhadap tujuantujuan berkinerja tinggi yang muncul di BBPBPTH (hanya 3,47\% yang menyatakan kurang setuju). Berdasarkan hal tersebut dapat dikatakan bahwa baik organisasi BBPBPTH maupun anggota organisasi BBPBPTH sama-sama memiliki perhatian terhadap tujuan-tujuan berkinerja tinggi yang baik karena fasilitas pendukung dan insentif yang diberikan BBPBPTH memadai untuk meningkatkan komitmen pegawai BBPBPTH dalam menghasilkan output kerja yang berbiaya rendah dan berkualitas dengan produktivitas tinggi.

\section{PENUTUP}

Dalam penelitian ini berhasil dibuktikan bahwa Iklim Komunikasi Organisasi yang tersusun atas Kepercayaan (Trust), Mendengarkan dalam komunikasi keatas (Listening in upward communication), dan Perhatian terhadap tujuan-tujuan berkinerja tinggi (Concern to high performance goals) memiliki pengaruh positif terhadap Komitmen Organisasi melalui perspektif aparatur sipil negara nonstruktural di BBPBPTH. Hal ini sekaligus memperkuat penelitian yang telah dilakukan beberapa peneliti sebelumnya.

Berdasarkan hasil penelitian, diketahui pula bahwa tidak semua faktor-faktor iklim komunikasi secara signifikan memberikan pengaruh terhadap komitmen organisasi melalui perspektif aparatur sipil negara non struktural di BBPBPTH. Mendengarkan dalam komunikasi ke atas (Listening in upward communication) tidak terbukti berpengaruh negatif terhadap Komitmen Organisasi.

Selain kepercayaan (Trust), Mendengarkan dalam komunikasi ke atas (Listening in upward communication), dan Perhatian terhadap tujuan-tujuan berkinerja tinggi (Concern to high performance goals) yang merupakan faktor-faktor iklim komunikasi organisasi yang diteliti, masih terdapat variabel lain sebesar $49,77 \%$ terkait faktor lain yang tidak diterangkan dalam penelitian ini 
yang dapat meningkatkan komitmen organisasi. Oleh karena itu, penelitian lanjutan sangat disarankan untuk memperkaya khazanah keilmuan. Dalam penelitian ini, peneliti sengaja membatasi penelitian dengan mengambil perspektif aparatur sipil negara non struktural, tetapi jika berbicara tentang iklim komunikasi yang melibatkan gabungan persepsi dari seluruh anggota organisasi, disarankan untuk penelitian selanjutnya untuk mengambil perspektif dari tingkat pimpinan organisasi pemerintah.

Agar komitmen organisasi dari para anggota organisasi dapat terus terpupuk, disarankan agar para manager yang dalam penelitian ini adalah pegawai struktural dapat menjaga kepercayaan yang sudah terbentuk dalam organisasi tersebut serta memupuk komunikasi efektif antaranggota organisasi agar memudahkan koordinasi dalam berorganisasi.

\section{Ucapan Terima Kasih}

Penulis mengucapkan rasa apresiasi dan terima kasih kepada seluruh jajaran pimpinan dan karyawan Balai Besar Penelitian Bioteknologi dan Pemuliaan Tanaman Hutan (BBPBPTH) atas izin dan kesediaannya berpartisipasi dalam penelitian ini serta apresiasi kepada para dosen pembimbing: Prof.Dr. Y.A.N. Prajarto, Dr. Muhammad Sulhan, dan Prof. Dr. Ir. Dewa Ketut Sadra Swastika, MS. yang telah bersedia memberikan saran dan koreksi dalam penelitian dan penulisan karya tulis ini.

\section{DAFTAR PUSTAKA}

Bahrami, M. A., Barati, O., Ghoroghchian, M., Montazer-alfaraj, R., \& Ezzatabadi, M. R. (2016). Role of Organizational Climate in Organizational Commitment: The Case of Teaching Hospitals. Osong Public Health Res Perspect., 7(2), 96-100. https://doi.org/10.1016/j.phrp.2015.11.009

Dillard, J. P., Wigand, R. T., \& Boster, F. J. (1986). Communication climate and its role in organizations. Communications, 12(2), 83-101. https://doi.org/http://dx.doi.org/10.1515/comm.1986.12.2.83

Fauzi, A., \& Sarwoprasodjo, S. (2014). Influencing of Organizational Climate Communication to Job Performance in Situ Udik Rural Government. Jurnal Sosiologi Pedesaan, 2(3), 124-134. Retrieved from https://journal.ipb.ac.id/index.php/sodality/article/view/9420

Guney, S., Diker, O., Guney, S., Ayranci, E., \& Solmaz, H. (2012). Effects of Organizational Communication on Work Commitment: A Case Study on a Public Agency in Ankara. Business Management Dynamics, 2(4), 18-29.

Guzley, R. M. (1992). Organizational Climate and Communication Climate Predictors of Commitment to the Organization. Management Communication Quarterly, 5(4), 379-402. https://doi.org/https://doi.org/10.1177/0893318992005004001

Hardjana, A. (2007). Iklim Komunikasi Keorganisasian. Jurnal Ilmu Komunikasi, 4(2), 179-231.

Harrison, T. R., \& Doerfel, M. L. (2006). Competitive and Cooperative Conflict Communication Climate: The Influence of Ombuds Process on Trust and Commitment to The Organization. International $\begin{array}{llll}\text { Journal of } & \text { Conflict } & \text { Management, } & 17(2),\end{array}$ https://doi.org/https://doi.org/10.1108/10444060610736611

Hosseini, M., \& Talebian, N. H. (2015). Correlation between organizational commitment and organizational climate of physical education teachers of schools of Zanjan. International Journal of Sport Studies, $5(2), 181-185$.

Latan, H., \& Ghozali, I. (2012). Partial Least Squares: Konsep, Teknik dan Aplikasi Menggunakan Smart PLS 2.0 M3. Semarang: Universitas Dipenegoro.

Meyer, J. P., \& Allen, N. J. (1997). Commitment in the Workplace,Theory, Research, and Application (First). California: Sage Publication.

Mowday, R. T., Porter, L. W., \& Steers, R. M. (1982). Employee Organization Lingkages : The Pyschology of Commitment, Absenteeism, and Turnover. New York: Academic Press. https://doi.org/https://doi.org/10.1016/C2013-0-11207-X

Pace, W. R., \& Faules, D. F. (1993). Organizational Communication. New Jersey: Prentice Hall. 
Palupi, A. A. (2014, October). Kawal Dampak Pembangunan KLH-Kemenhut. Retrieved 20/1/2019 from https://nationalgeographic.grid.id/read/13294833/penggabungan-kementerian-dikhawatirkan-aktivislingkungan?page=all on 05 November 2014.

Palupi, S. S. (2004). Hubungan Kepuasan Kerja dan Iklim Komunikasi dalam Organisasi terhadap Komitmen Organisasi. Universitas Indonesia.

Rafiee, N., Bahrami, M. A., \& Entezarian, S. (2015). Demographic determinants of organizational commitment of health managers in Yazd Province. International Journal of Management, Accounting and Economics, 2(1), 91-100.

Rogers, D. P. (1987). Relationships Between Communication Climate Variables and Organizational Commitment: The Case of a Food Processing Plant. Academy of Management Proceedings, 1. https://doi.org/https://doi.org/10.5465/ambpp.1987.17534202

Sanusi, A. (2012). Pengaruh motivasi kerja, iklim komunikasi terhadap komitmen keorganisasian pegawai Arsip Nasional Republik Indonesia. Universitas Indonesia.

Tan, H., \& Lim, A. (2009). Trust in Coworkers and Trust in Organizations. The Journal of Pyschology, 143(1), 45-66. https://doi.org/10.3200/JRLP.143.1.45-66

Tansky, J. W., \& Cohen, D. J. (2001). The Relationship between Organizational Support, Employee Development, and Organizational Commitment. Human Resource Quarterly, 12(3), 285-300.

Trombetta, J. J., \& Donald P.Rogers. (1988). Communication Climate, Job Satisfaction, and Organizational Commitment: The Effect of Information Adequacy, Communication Openness, and Decision Participation. Management Communication Quarterly, 1(4), 494-514. https://doi.org/https://doi.org/10.1177/0893318988001004003

Van Noordwijk, M., Bizard, V. Wangpakapattanawong, P. Tata, H. L., Villamor, G. B., \& Leimona, B. (2014). Tree covers transitions and food security in Southeast Asia. Global Food Security, 3. https://doi.org/10.1016/j.gfs.2014.10.005

Vuuren, M. van, Jong, M. D. T. de, \& Seydel, E. R. (2007). Direct and Indirect Effects of Supervisor Communication on Organizational Commitment. Corporate Communication International Journal, 2(2), 116-128.

Wang, Y. (2011). The Role of Communication in Enchancing Employees Organizational Commitment: Exploring the Relationship between Social-Emotional-oriented Communication, Work-oriented Communication and Organizational Commitment in China. Uppsala University. Retrieved 20/1/2019 from https://www.diva-portal.org/smash/get/diva2:600000/FULLTEXT01.pdf

Willemyns, M., Gallois, C., \& Callan, V. (2003). Trust me, I'm Your Boss: Trust and Power in SupervisorSupervisee Communication. International Journal of Human Resource Management, 14(1), 41-62. https://doi.org/https://doi.org/10.1080/09585190210158547

Zeffane, R. (2011). Communication, Commitment, \& Trust: Exploring The Triad. International Journal of Bussiness and Management, 6(6), 77-87.

Zulfah, S., Saridewi, M., \& Wira, W. (2018). Pengaruh Motivasi, Komunikasi, Komitmen Organisasi dan Iklim Organisasi Terhadap Kinerja Kryawan Di Pt. X. Universitas Maritim Raja Ali Haji. Retrieved 20/1/2019 from http://repository.umrah.ac.id/1692/1/SYARIFAH ZULFAH-140461201101-FEKON2018.pdf 